\title{
Helminthic parasites in indigenous chickens in Penang Island, Malaysia
}

\author{
Farah Haziqah, M.T. ${ }^{*}$ and Khadijah, S. ${ }^{2}$ \\ ${ }^{1}$ School of Biological Sciences, Universiti Sains Malaysia, 11800 USM, Pulau Pinang, Malaysia \\ ${ }^{2}$ Faculty of Food Science and Technology, Universiti Malaysia Terengganu, 21030 Kuala Terengganu, \\ Terengganu, Malaysia \\ *Corresponding author e-mail: farahhaziqah@usm.my \\ Received 25 February 2020; received in revised form 26 August 2020; accepted 27 August 2020
}

\begin{abstract}
Indigenous chicken (Gallus domesticus) is reared for both its meat and eggs. Most consumers prefer the meat probably due to its specific texture and taste. The study was conducted to determine the presence of helminth parasites of 240 indigenous chickens (Gallus domesticus) obtained randomly from 12 divisions in Penang Island, Malaysia. Necropsy findings revealed 14 endoparasite species which parasitized these chickens namely, Acuaria hamulosa, Acuaria spiralis, Amoebotaenia sphenoides, Ascaridia galli, Brachylaima sp., Capillaria spp., Gongylonema ingluvicola, Heterakis gallinarum, Hymenolepis sp., Oxyspirura mansoni, Raillietina echinobothrida, Raillietina tetragona, Syngamus trachea and Tetrameres americana. The high abundance of helminth species observed in this study may be attributed to the free-range scavenging production system, where these indigenous chickens were exposed to intermediate or paratenic hosts of helminths which infect poultry. Besides, sustainable methods of helminthic control measure are necessary in order to enhance indigenous chicken production and eventually improve the economy of the rural farmers.
\end{abstract}

\section{INTRODUCTION}

Most of rural villagers in Malaysia rear native chickens (Gallus domesticus) under the free-range system. The chickens are left scavenging around the backyards during daytime and during nights, usually confined in simple coops or allowed to rest on trees. They enjoy more freedom of movement as compared to chickens reared under the intensive system, where they are crammed and may lack movement. They find their feeds from the surrounding environment that takes the forms of kitchen wastes, broken grains, worms, snails, insects, vegetation, food remnants or offal. Indigenous chicken, which is also known as 'ayam kampung', is a dual-purpose type, reared for both its meat and eggs. However, it has a low egg-laying performance and the eggs are smaller than that of commercial chicken eggs. Generally, most consumers, probably due to the specific texture and taste, prefer their meat. Therefore, its meat is more expensive than that of broilers, more so they were free of antibiotics, growth hormones and other substances which are commonly used in conventional poultry farming. Nowadays, they become popular in rural households where there is an emerging trend of consumer awareness towards organically grown chickens, with customers increasingly willing to pay high prices for good quality meat.

The first checklist of helminths in domestic livestock, including poultry in Malaya was made by Lancaster (1957). Besides, Mustaffa-Babjee (1980), Shanta (1982) and Mustaffa-Babjee (1984) also made a similar listing. The last known checklist on parasites of domestic animals in Malaysia was prepared by Lee et al. (1991). Until this date, the most recent study on endoparasites 
in chickens was reported by Suhaila et al. (2015) who studied on commercial free-range chickens sourced from Alor Setar, Kedah.

Most of parasite studies of poultry were not from Penang Island, and studies on the prevalence and significance of helminths in poultry in Penang Island seems limited. The only two reports on the prevalence of parasites in poultry from Penang Island were that of Khairul and Khamis (1978) and Rahman et al. (2009). Therefore, this study was conducted to determine the prevalence of endoparasites in scavenging chickens from Penang Island. In addition, this study provides the latest checklist that offers the first large scale overview on endoparasite infestation of the Malaysian indigenous chicken population which is very useful in determining the appropriate and strategic control of helminthiasis as to improve the health and output of the indigenous chickens reared by the rural farmers or villagers in the study areas.

\section{MATERIALS AND METHODS}

\section{Sampling areas}

The study was carried out in Penang Island, Malaysia which is situated between latitudes $5^{\circ} 8^{\prime} \mathrm{N}$ to $5^{\circ} 35^{\prime} \mathrm{N}$ and longitudes $100^{\circ} 8^{\prime} \mathrm{E}$ to $100^{\circ} 32^{\prime} \mathrm{E}$ located on the North West coast of Peninsular Malaysia. This study was carried out in 12 divisions (Mukim) comprising of Pantai Acheh (Division 1), Teluk Bahang (Division 2), Balik Pulau (Division 5), Pondok Upeh (Division 6), Batu Pasir Panjang (Division 8), Bukit Gemuruh (Division 9), Teluk Kumbar (Division 11), Bayan Lepas (Division 12), Paya Terubong (Division 13), Tanjung Tokong (Division 18), Titi Teras (Division E) and Kongsi (Division F).

\section{Ethical approval}

All animal hosts in this study were handled according to protocols approved by the Animal Ethic Committee USM (AECUSM) (Case No.: USM / Animal Ethics Approval / 2011 / (65) (293)).

\section{Study animals}

The study was conducted on 240 scavenging chickens randomly obtained from various villages around Penang Island. The chickens are generally small with body weights ranging from 1.3 to $2.4 \mathrm{~kg}$. All the chickens were bought directly from the owners. Owners provided estimated age of the chickens. Twenty chickens (10 males and 10 females) were collected from each of the 12 divisions.

\section{Helminths examination}

The entire gastrointestinal tract was opened with a fine scissor and placed into separate petri dishes containing normal saline. The contents were washed with distilled water through a strainer while the deposits were transferred to a petri dish for examination. The mucosa was scraped in order to collect the embedded worms in the mucosal layer of crop, proventriculus and gizzard. Isolation of gizzard worm was preceded by peeling off the keratin layer. The trachea was directly examined while the kidneys were similarly treated and examined. The eyes were checked for eyeworms by lifting the eyelids. Eyeworms present were removed using blunt forceps. All worms were picked, recorded and stored in universal bottles containing 70\% ethanol (Gibbon et al., 1996).

Identification of the helminths was carried out by clearing in lactophenol with addition of a few drops of $10 \%$ lactic acid and examined under the light microscope. All helminths were identified by morphological characters according to Soulsby (1968). Dr. P. Chandrawathani from Veterinary Research Institute and an expert from University of Queensland, Australia, Assoc. Prof. Thomas Cribb confirmed the identification.

\section{Data analysis}

A one-way analysis of variance betweengroups, was conducted to explore the impact of age on the number of endoparasites found in the chickens whereas, an independentsamples t-test was conducted to indicate whether there are significant differences in the mean number of endoparasites for males and females. The prevalence of helminth species identified was calculated using a formula as described by Thrusfield (1995). 
Table 1. Prevalence and predilection site of helminthic parasites of scavenging chickens in Penang Island

\begin{tabular}{|c|c|c|c|c|c|}
\hline Endoparasites & $\begin{array}{c}\text { No. of } \\
\text { chickens } \\
\text { infested }\end{array}$ & $\begin{array}{c}\text { Prevalence } \\
(\%)\end{array}$ & $\begin{array}{l}\text { Mean worm } \\
\text { burden } \\
\pm \mathrm{SE}\end{array}$ & $\begin{array}{l}\text { Range of } \\
\text { helminths/ } \\
\text { chicken }\end{array}$ & $\begin{array}{l}\text { Predilection } \\
\text { sites }\end{array}$ \\
\hline \multicolumn{6}{|l|}{ Nematodes } \\
\hline Ascaridia galli & 49 & 20.4 & $0.58 \pm 0.123$ & $1-21$ & small intestine \\
\hline Acuaria hamulosa & 2 & 0.8 & $0.02 \pm 0.013$ & $1-3$ & gizzard \\
\hline Acuaria spiralis & 4 & 1.7 & $0.21 \pm 0.204$ & $0-49$ & proventriculus \\
\hline Capillaria spp. & 141 & 58.8 & $8.42 \pm 0.938$ & $1-65$ & $\begin{array}{c}\text { caeca/small } \\
\text { intestine }\end{array}$ \\
\hline Gongylonema ingluvicola & 33 & 13.8 & $0.97 \pm 0.243$ & $1-32$ & crop \\
\hline Heterakis gallinarum & 148 & 61.6 & $18.50 \pm 2.545$ & $1-235$ & caeca \\
\hline Oxyspirura mansoni & 1 & 0.4 & $0.13 \pm 0.125$ & $0-30$ & eye \\
\hline Tetrameres americana & 38 & 15.8 & $1.08 \pm 0.238$ & $1-26$ & proventriculus \\
\hline Syngamus trachea & 8 & 3.3 & $0.06 \pm 0.026$ & $1-5$ & trachea \\
\hline \multicolumn{6}{|l|}{ Cestodes } \\
\hline Amoebotaenia sphenoides & 94 & 39.2 & $29.58 \pm 5.946$ & $1-736$ & duodenum \\
\hline Hymenolepis sp. & 86 & 35.8 & $29.81 \pm 7.320$ & $1-1200$ & duodenum \\
\hline Rallietina tetragona & 104 & 43.3 & $5.33 \pm 0.745$ & $1-112$ & small intestine \\
\hline Raillietina echinobothrida & 121 & 50.4 & $6.92 \pm 0.934$ & $1-80$ & small intestine \\
\hline \multicolumn{6}{|l|}{ Trematodes } \\
\hline Brachylaima sp. & 1 & 0.4 & 0 & 1 & caeca \\
\hline
\end{tabular}

\section{RESULTS}

Fourteen different endoparasites were identified which consisted of nine species of nematodes, four cestodes and one trematode. The nematodes recovered were $A$. galli, $A$. hamulosa, A. spiralis, Capillaria spp., G. ingluvicola, H. gallinarum, O. mansoni, $S$. trachea and $T$. americana. The cestodes encountered were Hymenolepis sp., $R$. echinobothrida, $R$. tetragona and $A$. sphenoides. Brachylaima sp. was the only trematode species found out of 240 scavenging chickens.

The mean abundance, prevalence, range and predilection sites of parasites were summarized in Table 1. It was found that the highest prevalence in nematode was $H$. gallinarum with $61 \%$, while $R$. echinobothrida recorded the highest prevalence in cestodes with 50\%. Meanwhile, Brachylaima $\mathrm{sp}$. was the only trematode species found with $0.4 \%$. The highest mean worm burden was recorded for the cestode, $A$. sphenoides with a mean worm burden of $29.8( \pm 5.946)$ while the lowest was the nematode, $S$. trachea with a mean worm burden of $0.1( \pm 0.026)$ (Table 2).
Table 2. Total worm counts of helminths

\begin{tabular}{lc}
\hline Endoparasites & $\begin{array}{c}\text { Total worm } \\
\text { counts }\end{array}$ \\
\hline Nematodes & $156(0.6 \%)$ \\
Ascaridia galli & $4(0.01 \%)$ \\
Acuaria hamulosa & $49(0.2 \%)$ \\
Acuaria spiralis & $2104(7.8 \%)$ \\
Capillaria spp. & $232(0.9 \%)$ \\
Gongylonema ingluvicola & $4329(16 \%)$ \\
Heterakis gallinarum & $40(0.15 \%)$ \\
Oxyspirura mansoni & $258(1 \%)$ \\
Tetrameres americana & $173(0.6 \%)$ \\
Syngamus trachea & \\
Cestodes & $7094(26.2 \%)$ \\
Amoebotaenia sphenoides & $9709(35.9 \%)$ \\
Hymenolepis sp. & $1651(6.1 \%)$ \\
Raillietina echinobothrida & $1274(4.7 \%)$ \\
Raillietina tetragona & \\
Trematodes & $1(0.004 \%)$ \\
Brachylaima sp. & \\
\hline
\end{tabular}

\section{DISCUSSION}

The findings in the present study recovered the highest number of endoparasites species found from indigenous chickens with a total of 14 different species as compared to the prior reports on the prevalence of parasites 
in poultry from Penang Island whereby both Khairul and Khamis (1978) and Rahman et al. (2009) found just eight species of helminths respectively. Khairul and Khamis (1978) examined the occurrence of helminthic parasites from 100 intestines of chickens reared under different conditions obtained from the Jelutong market, which supplied caged and free-ranged chickens whereby Rahman et al. (2009) examined only 60 rural scavenging chickens. Most of the previous studies were limited to a small number of samples thus contribute to the small number of helminth species reported by them as compared to this study with a total of 14 species of helminths recovered from 240 chicken sampled.

In the present study, multiple endoparasite infections were recorded in most of the examined chickens, as similarly reported by Khairul and Khamis (1978). The highest percentage of chickens was recorded with triple endoparasites infections. However, none was found infected with all 14 species of parasites and majority of parasites recovered in this study were gastrointestinal parasites. High species richness among indigenous chickens with scavenging habit is expected because there is accessibility to infective material involving the infective eggs or intermediate hosts such as snails, beetles or cockroaches whereby they might pick up these infective materials from the contaminate the environment as they feed and scavenge for food (Ola-Fadunsin et al., 2019).

Most of the nematode species identified in this study have been previously recorded by various researchers (Lancaster, 1957; Omar \& Lim, 1968; Mustaffa-Babjee, 1980, 1984; Shanta, 1982; Sani et al., 1986; Lee et al., 1991). Certain nematodes such as Dispharynx spp. and Acuaria spp. caused ulceration and inflammation to the surrounding tissues (Lim, 1971). However, there was no pathological effect caused by nematodes observed in this study, except for high infections of $H$. gallinarum whereby nodules were seen on the mucosa of caeca.

Four species of cestodes were found in this present study, as similarly reported by Rahman et al. (2009), although Khairul and Khamis (1978) have reported five. $R$. echinobothrida was the most common cestode in this study, as reported by Vattanodorn et al. (1984), Sani et al. (1986), Amin-Babjee et al. (1997) and Suhaila et al. (2014). However, Shanta et al. (1971) and Amin-Babjee and Lee (1994) reported that $R$. tetragona was the most frequent cestode in chickens.

Brachylaima sp. was the only trematode species recovered in this study. It has not been recorded in previous local checklist of parasites of domestic chickens and thus was observed for the first time in the country. This trematode was found in the caeca of one examined chicken. Terrestrial snails are the intermediate hosts for this trematode. Infection occurs when the host eats the intermediate host containing the infective metacercaria. Other trematode species were also known to be present in chickens, such as Echinostoma lindoense were reported by Shanta et al. (1971) whereas Prosthogonimus sp., Heterophyes sp. and Echinostoma revolutum were reported in chickens from aborigine settlements by Vattanodorn et $a l$. (1984). Meanwhile, the kidney fluke, Tanaisia zarudnyi was found in domestic chickens (Lee \& Amin-Babjee, 1987; AminBabjee et al., 1997) as well as Malayan red jungle fowls (Lee et al., 1985).

Shanta et al. (1971) made actual enumerations of roundworms but not those of tapeworms. However, the present study made enumerations of all helminths but not protozoans. The highest worm count was the cestode, Hymenolepis sp., although Khairul and Khamis (1978) showed that $R$. tetragona was the highest compared to the other species. The reason for the large numbers of tapeworms in scavenging chickens is probably due to the occurrence of the intermediate hosts such as beetles, ants and cockroaches, which known to be very common and abundant in the environment and thus predisposes them to high prevalence and heavy parasite burden. Meanwhile, the lowest worm count was Brachylaima sp. with only one single fluke recovered. This may be attributed to the fact that most trematodes have a complex life cycle involving two or more hosts as well as asexual and sexual reproductions in its life cycle. 
The highest prevalence rate in the present study was demonstrated in $H$. gallinarum as similarly reported by Khairul and Khamis (1978) which could be associated with the peculiarity in its life cycle in which the eggs could remain viable in the soil for several months (Taylor et al., 2007). Apart from that, these findings may be attributed to the food searching habits of chickens, scratching the soil surface where most infective stages of nematodes are hidden. Infections are induced by ingesting the infective stages of nematodes.

A few evidences have been presented to account for age resistance. According to Sandground (1929), age resistance is an extension of natural resistance. It is because a parasite develops normally only in animals which provide a favourable physiological medium. Therefore, only abnormal hosts would show a definite age resistance. Another view suggested by Cort and Otto (1940) is that the young animals' antibody response is slower than adult animals. Therefore, the young are more susceptible than adult. Infections might be by chance, as they enjoy more freedom of movement compared to chickens reared under the intensive system.

It is well known that susceptibility to parasites probably is contributed to by sex differences. There are number of evidences that showed sex hormones in vertebrate animals increase resistance to parasitism; female hosts were regarded as being more resistant than males. Dobson (1961b) and Behnke (1975) claimed that female hormone is involved in increasing resistance in mammals. Dobson (1961a) indicated that male hormones seem to favour growth and survival of parasites. This is consistent with Chandler (1943) and Addis (1946) who found that testosterone favoured the growth of $H$. diminuta in rats. Findings by Khairul and Khamis (1978) reported that the mean abundance of endoparasites was higher in males compared to females. It shows there was a tendency for males to be more heavily infested with parasites than females. In addition, the sex differences may also vary considerably as the host grows older (Mathies, 1954; Haley, 1958; Gray, 1972).
These may be correlated with the structural and functional alterations associated with the attainment of sexual maturity.

\section{CONCLUSION}

In the present study, abundance of helminth species has been recorded in indigenous chickens. Some are known to be pathogenic and may contribute significantly to the low productivity. The precise knowledge, on which parasites are involved, might in the long-term lead to a better understanding of the mechanisms involved in poultry parasitism and may lead to higher productivity. This information is vital, especially to the poultry farmers as well as the veterinary officers to facilitate the isolation and identification of parasitic problems in backyard and industrial poultry production systems.

Acknowledgements. The authors would like to thank Universiti Sains Malaysia (304/PBIOLOGI/6315156) for funding this study. Furthermore, several people at the Veterinary Research Institute (VRI) Ipoh, Perak for their kindness and assistance during the identification process for this study.

\section{Conflict of Interests}

The authors declare that they have no conflict of interests.

\section{REFERENCES}

Addis, C.J. (1946). Experiments on the relation between sex hormones and the growth of tapeworms. Journal of Parasitology 32: 574-580.

Amin-Babjee, S.M. \& Lee, C.C. (1994). Parasites of the fighting breed of domestic chicken, Gallus gallus domesticus. In: Applied Biology beyond the Year 2000. Third Symposium of Malaysian Society of Applied Biology, M.K. Vidyadaran and S.C. Quah (Eds). Malacca. pp. 16-18. 
Amin-Babjee, S.M., Lee, C.C. \& Mahmood, A.A. (1997). Prevalence of cestode and trematode in different age groups of village chickens. Journal of Veterinary Malaysia 9 (2): 61-65.

Behnke, J.M. (1975). Aspiculuris tetraptera in wild Mus musculus. The prevalence of infection in male and female mice. Journal of Helminthology 49: 85-90.

Chandler, A.C. (1943). Studies on the nutrition of tapeworms. American Journal of Hygiene 37: 121-130.

Cort, W.W. \& Otto, G.F. (1940). Immunity in hookworm diseases. Rev. Gastroenterol 7: 3-13.

Dobson, C. (1961a). Certain aspects of the host-parasite relationship of Nematospiroides dubius (Baylis). I. Resistance of male and female mice to experimental infections. Parasitology 51: 173-179.

Dobson, C. (1961b). Certain aspects of the host-parasite relationship of Nematospiroides dubius (Baylis). II. The effect of sex on infections in the rat (an abnormal host). Parasitology 51: 499510.

Gibbons, L.M., Jones, A. \& Kahlil, L.F. (1996). Laboratory manual for eighth international training course on identification of parasites of economic importance. UK: CABI Institute of Parasitology; 1996.

Gray, J.S. (1972). The effect of host age on the course of infection of Raillietina cesticillus (Molin, 1858) in the fowl. Parasitology 65: 235-241.

Haley A.J. (1958). Sex difference in the resistance of hamsters to infection with the rat nematode, Nippostrongylus muris. Experimental Parasitology 7: 338-348.

Khairul, A.A. \& Khamis, S. (1978). Helminth parasites of Gallus domesticus in Penang Island. Medical Journal of Malaysia 33: 186-192.

Lancaster, W.E. (1957). A check-list of helminths of domestic livestock in Malaya. Journal of Malaya Veterinary Medical Association 1: 151-163.
Lee, C.C. \& Amin-Babjee, S.M. (1987). Tanaisia zarudnyi vietnamensis Odening, 1963 from an indigenous domestic fowl Gallus domesticus L. Kajian Veterinar 19: 219-221.

Lee, C.C., Krishnasamy, M., Amin-Babjee, S.M. \& Dunsmore, J.D. (1985). Tanaisia (Tamerlania) zarudnyi vietnamensis Odening, 1963 (Eucotylidae: Trematoda) from the red jungle fowl Gallus gallus spadiceus in Peninsular Malaysia. Tropical Biomedicine 2: 93-97.

Lee, C.C., Sani, R.A., Amin-Babjee, S.M., Jeffery, J. \& Krishnasamy, M. (1991). Checklist of arthropods, protozoa and helminthes of domestic animals. Journal Veterinary Malaysia 3: 45-57.

Lim, C. (1971). Parasites of the alimentary tract of poultry in Singapore. Kajian Veterinar 3: 1-9.

Mathies, A.W. (1954). The influence of sex on mouse pinworm infection. Journal of Parasitology 40: 702.

Mustaffa-Babjee, A. (1980). Checklist of diseases parasites and organisms of domestic animals in Malaysia. Division of Veterinary Publication, Ministry of Agriculture, Malaysia.

Mustaffa-Babjee, A. (1984). Checklist of diseases, parasites and pathogenic organisms of domestic animals in Malaysia. Division of Veterinary Publication, Ministry of Agriculture, Malaysia. pp. 28.

Ola-Fadunsin, S.D., Uwabujo, P.I., Sanda, I.M., Ganiyu, I.A., Hussain, K., Rabiu, M., Elelu, N., \& Alayande, M.O. (2019). Gastrointestinal helminths of intensively managed poultry in Kwara Central, Kwara State, Nigeria: Its diversity, prevalence, intensity, and risk factors. Veterinary World 12(3): 389-396. https:// doi.org/10.14202/vetworld.2019.389-396

Omar, A.R. \& Lim, S.Y. (1968). Diseases of Poultry 1961-1966. Kajian Veterinar 1(4): 224-235. 
Rahman, A.W., Salim, H. \& Ghause, M.S. (2009). Helminthic parasites of scavenging chickens (Gallus domesticus) from villages in Penang Island, Malaysia. Tropical Life Sciences Research 20: 1-6.

Sandground, J.H. (1929). A consideration of the relation of host-specificity of helminthes and other metazoan parasites to the phenomena of age resistance and acquired immunity. Parasitology 21: 227-253.

Sani, R.A., Harisah, M. \& Bohari, Y. (1986). Parasites of the indigenous fowl (Gallus gallus domesticus) in Selangor. Kajian Veterinar 18(2): 183-189.

Shanta, C.S. (1982). A revised check-list of helminths of domestic animals in West Malaysia. Malaysia Veterinary Journal 7: 180-193.

Shanta, C.S., Song, C.Y. \& Wan, S.P. (1971). Helminth parasites of the alimentary tract of broilers in North Malaya. Malaysian Veterinary Journal 5: 1-8.
Suhaila, A.H., Sabrina, D.L., Nik Ahmad Irwan Izzauddin, N.H., Khadijah, S. \& Hamdan, A. (2015). Prevalence study of parasites in commercial free-range chickens. Malaysian Journal of Veterinary Research 6(2): 47-58.

Taylor, M.A., Coop, R.L. \& Wall, R.L. (2007). Veterinary Parasitology. 3rd ed. Oxford: Blackwell Publishing Ltd; p. 809.

Thrusfield (1995). Veterinary Epidemiology. 2nd Edition, Blackwell Science, Cambridge.

Vattanodorn, S., Inder-Singh, K. \& Krishnasamy, M. (1984). A preliminary survey of helminth endoparasites of the domestic fowl Gallus domesticus L. from aborigine settlements with some new records. Malaysian Veterinary Journal 8: 13-18. 